\title{
Hypomagnesemia at the time of autologous stem cell transplantation for patients with diffuse large B-cell lymphoma is associated with an increased risk of failure
}

Jennifer J. Gile (1)', Camden L. Lopez $\mathbb{E}^{2}$, Gordon J. Ruan', Matthew A. Hathcock², Jithma P. Abeykoon', Joy R. Heimgartner ${ }^{3}$, Nikola A. Baumann ${ }^{4}$, M. Molly McMahon ${ }^{3}$, Ivana N. Micallef', Patrick B. Johnston?', Jose C. Villasboas Bisneto', Luis F. Porrata', Jonas Paludo (1)', Stephen M. Ansell', William J. Hogan (1) and Thomas E. Witzig (1D)

\begin{abstract}
Magnesium is an essential element that is involved in critical metabolic pathways. A diet deficient in magnesium is associated with an increased risk of developing cancer. Few studies have reported whether a serum magnesium level below the reference range (RR) is associated with prognosis in patients with diffuse large B cell lymphoma (DLBCL). Using a retrospective approach in DLBCL patients undergoing autologous stem cell transplant (AHSCT), we evaluated the association of hypomagnesemia with survival. Totally, 581 patients eligible for AHSCT with a serum magnesium level during the immediate pre-transplant period were identified and $14.1 \%(82 / 581)$ had hypomagnesemia. Hypomagnesemia was associated with an inferior event-free (EFS) and overall survival (OS) compared to patients with a serum magnesium level within RR; median EFS: 3.9 years ( $95 \%$ Cl: 1.63-8.98 years) versus 6.29 years ( $95 \%$ Cl: $4.73-8.95$ years) with HR 1.63 (95\% Cl: 1.09-2.43, $p=0.017$ ) for EFS, and median OS: 7.3 years (95\% Cl: 2.91 -upper limit not estimable) versus 9.7 years ( $95 \%$ Cl: 6.92-12.3 years) with HR 1.90 (95\% Cl: $1.22-2.96, p=0.005$ ) for OS months $0-12$, respectively. These findings suggest a potentially actionable prognostic factor for patients with $\mathrm{DLBCL}$ undergoing AHSCT.
\end{abstract}

\section{Introduction}

Diffuse large B cell lymphoma (DLBCL) is the most common subtype of non-Hodgkin lymphoma (NHL) ${ }^{1}$. First-line treatment for DLBCL is typically based on rituximab plus cyclophosphamide, doxorubicin, vincristine, and prednisone (R-CHOP) backbone which cures approximately $60 \%$ of patients ${ }^{2-4}$. Patients who fail $\mathrm{R}$ -

\footnotetext{
Correspondence: Thomas E. Witzig (Witzig.Thomas@Mayo.Edu)

'Division of Hematology, Department of Medicine, Mayo Clinic Rochester,

Rochester, MN 55905, USA

${ }^{2}$ Department of Biomedical Statistics and Informatics, Mayo Clinic Rochester,

Rochester, MN 55905, USA

Full list of author information is available at the end of the article

These authors contributed equally: Jennifer J. Gile, Camden L. Lopez
}

$\mathrm{CHOP}$ and meet the requirements for autologous hematopoietic stem cell transplant (AHSCT) are treated with salvage chemotherapy and if they have the sensitive disease, proceed to stem cell harvest and $\mathrm{AHSCT}^{5-7}$. AHSCT typically induces sustained remission in $40 \%$ of these patients; thus, relapse post-AHSCT remains an important issue ${ }^{8}$. The most important predictor of OS in these patients is the time from AHSCT to progression? Efforts to improve the outcome of AHSCT have included changes in the stem cell collection technique to enrich immune cells ${ }^{10-12}$ and to enhance stem cell numbers ${ }^{13}$; the preparatory regimens have changed little. There have also been improvements in the therapy of those patients

\section{(c) The Author(s) 2021}

(cc) Open Access This article is licensed under a Creative Commons Attribution 4.0 International License, which permits use, sharing, adaptation, distribution and reproduction BY in any medium or format, as long as you give appropriate credit to the original author(s) and the source, provide a link to the Creative Commons license, and indicate if changes were made. The images or other third party material in this article are included in the article's Creative Commons license, unless indicated otherwise in a credit line to the material. If material is not included in the article's Creative Commons license and your intended use is not permitted by statutory regulation or exceeds the permitted use, you will need to obtain permission directly from the copyright holder. To view a copy of this license, visit http://creativecommons.org/licenses/by/4.0/. 
who relapse after AHSCT with the recent approval of CAR-T cell therapy ${ }^{14}$.

In our quest to discover other actionable prognostic factors in the AHSCT group, we turned to the evaluation of nutritional factors in light of the recent discovery of Xlinked immunodeficiency with magnesium defect, Epstein-Barr virus, and neoplasia (XMEN) disease which suggests a role of magnesium in the development of hematologic malignancies and lymphocyte function ${ }^{15}$. $\mathrm{XMEN}$ is a primary immunodeficiency and congenital disorder of glycosylation ${ }^{16}$ caused by null mutations in the MAGT1 gene which codes for a magnesium transporter that is a regulator of intracellular magnesium levels ${ }^{17}$. These studies demonstrate that magnesium deficiency leads to impaired immune reactivity ${ }^{18}$. Recently, we identified that hypomagnesemia at baseline is associated with an inferior OS in patients with Burkitt Lymphoma ${ }^{19}$. In order to evaluate the impact of hypomagnesemia in DLCBL outcome, we studied DLBCL patients proceeding to AHSCT since they typically have a pretransplant magnesium level, uniform conditioning, and specified standard post-AHSCT follow-up through year 1. Based on the data from XMEN disease and previous work that early absolute lymphocyte count (ALC) recovery predicts superior survival after $\mathrm{AHSCT}^{10}$, we hypothesized that patients with low magnesium levels prior to AHSCT would have a higher risk of relapse at day 100 and that hypomagnesemia would affect the recovery of lymphocytes (ALC recovery) at day +15 .

\section{Methods}

\section{Study population}

The study was reviewed and approved by Mayo Clinic institutional review board. We utilized the Mayo Clinic Transplant Database to identify all patients greater than 18 years of age with a diagnosis of relapsed or refractory DLBCL that had failed first-line therapy, had the chemosensitive disease to salvage therapy, and were deemed eligible for AHSCT by the Lymphoma Transplant Physician group. The included patients underwent their first AHSCT in the Mayo Clinic Health Systems between January 1, 1998, and May 26, 2020. Prior to reinfusion of stem cells on day 0 , all patients received a conditioning regimen which started on day -6 . Using the database, we cross-referenced this search with patients who had a serum magnesium level (reference range: $1.7-2.6 \mathrm{mg} / \mathrm{dL}$ ) performed in the Mayo Clinic clinical laboratory as part of their standard pretransplant evaluation workup between days -28 to -7 . We chose days -28 to day -7 as it was typically the time period of stem cell evaluation and harvest while avoiding any effects of the conditioning chemotherapy on the magnesium level. Patients without serum magnesium in this window were excluded. Patients were considered to have hypomagnesemia if the magnesium level was less than the lower laboratory limit of $1.7 \mathrm{mg} / \mathrm{dL}$. Electronic medical records were reviewed for demographics, baseline performance status, and the calcium, platelet count, creatinine, aspartate aminotransferase (AST), alkaline phosphatase, and ALC between 7 and 28 days prior to transplant. In the case of multiple values for these factors, the one closest to day -7 was used. These data were collected as part of the standard reporting guidelines of the center for international blood and marrow transplant research (CIBMTR) of which Mayo Clinic is a member.

\section{Statistical analysis}

The association of hypomagnesemia with clinical and demographic factors was assessed using logistic regression. Variables with a $p$ value $<0.1$ in univariate analysis were included in a multivariate analysis. The association of hypomagnesemia and other factors with posttransplant survival was assessed using Cox proportional hazards regression. The primary survival outcome was overall survival (OS). OS was defined as the time from transplant until death or last follow-up. The secondary outcome was event-free survival (EFS) with events defined as relapse, re-transplantation, or death due to any cause. For the outcomes of 100-day and 1-year OS and EFS, event times were censored at 100 days and at 365 days, respectively, if an event (or loss of follow-up) had not occurred by that time. We used these relatively short follow-up times as we hypothesized that hypomagnesemia at the time of diagnosis would be associated with early clinical failure and also that long-term survival would be more difficult to link to a single pretransplant magnesium level. Survival curves were plotted with Kaplan-Meier methodology ${ }^{20}$. The relationship between magnesium level and OS or EFS was further investigated using Cox proportional hazards models in which continuous magnesium levels were modeled with a cubic spline with three knots to allow for nonlinearity. $p$ Values were two-sided and were not adjusted for multiple testing. All statistical analyses were performed using $\mathrm{R}$ version 3.6.2.

\section{Results \\ Patient characteristics}

Of 739 patients with relapsed or refractory DLBCL undergoing AHSCT at Mayo Clinic during this time period, $581(78.6 \%)$ patients had a magnesium level available prior to their conditioning regimen and were eligible for inclusion in the analyses. Of these patients, $14.1 \%(82 / 581)$ had hypomagnesemia with a median magnesium level of $1.6 \mathrm{mg} / \mathrm{dL}$ (1.0-1.6); the remaining $86 \%$ had magnesium levels within the RR with a median level of $1.9 \mathrm{mg} / \mathrm{dL}(1.7-2.6)$. The median number of days prior to undergoing transplant that a magnesium level was collected was 7 days (7-28 days). 
Table 1 Pretransplant laboratory values in all patients and by normal or low pretreatment serum magnesium level categories.

\begin{tabular}{|c|c|c|c|c|c|}
\hline \multirow[t]{3}{*}{ Variables } & \multirow{3}{*}{$\begin{array}{l}\text { All patients } \\
N=581\end{array}$} & \multirow{3}{*}{$\begin{array}{l}\mathrm{Mg} \text { within the } \\
\text { reference range } \\
(1.7-2.3 \mathrm{mg} / \mathrm{dL}) \\
N=499\end{array}$} & \multirow{3}{*}{$\begin{array}{l}\text { Low } \mathrm{Mg} \\
\begin{array}{l}(<1.7 \mathrm{mg} / \mathrm{dL}) \\
N=82\end{array}\end{array}$} & \multirow[t]{3}{*}{$p$ Value* } & \multirow[t]{3}{*}{ Multivariate analysis } \\
\hline & & & & & \\
\hline & & & & & \\
\hline Age, years; median (range) & $62(19-78)$ & $62(19-78)$ & $62(23-78)$ & 0.09 & 0.38 \\
\hline \multicolumn{6}{|l|}{ Gender (\%) } \\
\hline Male & $60.80 \%$ & $62.50 \%$ & $50 \%$ & 0.03 & 0.015 \\
\hline Female & $39.20 \%$ & $37.50 \%$ & $50 \%$ & & \\
\hline Race (\% Caucasian) & $91.20 \%$ & $91.60 \%$ & $89.00 \%$ & 0.45 & \\
\hline Magnesium; median (range) & 1.9 & 1.9 & 1.6 & & \\
\hline$(1.0-2.6)$ & $(1.7-2.6)$ & $(1.0-1.6)$ & & & \\
\hline \% BEAM conditioning regimen & $78.30 \%$ & $77.20 \%$ & $82.50 \%$ & 0.33 & \\
\hline \% Peripheral blood stem cell source & $95.80 \%$ & $96.30 \%$ & $98.40 \%$ & 0.22 & \\
\hline $\begin{array}{l}\text { \% Patients with calcium }<8.5 \text { or }>10.0 \\
\mathrm{mg} / \mathrm{dL}\end{array}$ & $41(7.1 \%)$ & $33(7.5 \%)$ & $8(11.1 \%)$ & 0.3 & \\
\hline $\begin{array}{l}\text { Pretransplant ALC } \times 10(9) / L \text {; median } \\
\text { (range) }\end{array}$ & $0.83(0.11-11.94)$ & $0.85(0.11-11.94)$ & $0.81(0.15-5.23)$ & 0.77 & \\
\hline $\begin{array}{l}\% \text { Patients with ALC }<0.5 \times 10^{9} / \mathrm{L} \\
\text { pretransplant }\end{array}$ & $139(23.9 \%)$ & $120(24.1 \%)$ & $19(23.2 \%)$ & 0.85 & \\
\hline Platelet count $\times 10^{9} / \mathrm{L}$; median (range) & $119.0(10.0-669.0)$ & $122.5(10.0-669.0)$ & $95.0(15.0-315.0)$ & $<0.001$ & $<0.001$ \\
\hline $\begin{array}{l}\% \text { Patients with platelet count } \\
<150 \times 10^{9} / \mathrm{L}\end{array}$ & $400(68.6 \%)$ & $336(68.9 \%)$ & $64(80 \%)$ & 0.045 & \\
\hline$\%$ Patients with Albumin $\leq 3.5 \mathrm{~g} / \mathrm{dL}$ & $19(3.3 \%)$ & $16(4.1 \%)$ & $3(4.7 \%)$ & 0.81 & \\
\hline$\%$ Patients with AST >50 U/L & $48(8.3 \%)$ & $43(8.6 \%)$ & $5(6.1 \%)$ & 0.44 & \\
\hline$\%$ Patients with ALP $\geq 130 \mathrm{U} / \mathrm{L}$ & $403(69.4 \%)$ & $342(68.7 \%)$ & $61(74.4 \%)$ & 0.3 & \\
\hline Creatinine mg/dL; median (range) & $0.9(0.4-2.9)$ & $0.9(0.4-2.5)$ & $0.95(0.40-2.90)$ & 0.09 & 0.03 \\
\hline$\%$ Patients with creatinine $\geq 1.3 \mathrm{mg} / \mathrm{dL}$ & $66(11.4 \%)$ & $52(10.4 \%)$ & $14(17.1 \%)$ & 0.08 & \\
\hline
\end{tabular}

* $p$ Value between normal and low magnesium groups.

Abbreviations: ALC absolute lymphocyte count, AST aspartate aminotransferase, ALP alkaline phosphatase, Mg magnesium, BEAM (carmustine (BCNU), etoposide, cytosine arabinoside, and melphalan).

A comparison of baseline characteristics of patients with hypomagnesemia vs. magnesium level within RR is included is summarized in Table 1 . Patients were categorized according to the American Society of Blood and Marrow Transplantation risk categories for patients undergoing AHSCT. Totally, 87.7\% of patients with low serum magnesium were considered low risk compared to $83.5 \%$ of patients with serum magnesium levels within RR $(p=0.41)$.

On univariate analysis, male gender (OR 0.599, 95\% CI: $0.374-0.959 ; p=0.033$ ) and higher platelet count (OR 0.518 per doubling, $95 \%$ CI: $0.376-0.706 ; p<0.001)$ were significantly associated with having serum magnesium levels within RR; higher ALP (OR 1.464 per doubling, 95\%
CI: $1.029-2.103 ; p=0.036)$ was associated with a low serum magnesium level. Totally, 122 patients were missing a corresponding serum albumin level within the day -28 to day -7 timeframe; thus, the multivariate analyses were performed with and without serum albumin levels. Multivariate logistic regression on baseline variables (excluding albumin) with $p<0.1$ on univariate regression demonstrated that gender $(p=0.011)$, platelets $(p<0.001)$, and creatinine $(p=0.020)$ were significantly associated with magnesium levels (Table 1). When albumin was included, multivariate logistic regression on baseline variables with $p<0.1$ on univariate regression demonstrated that only platelets $(p<0.001)$ were significantly associated with magnesium level. 


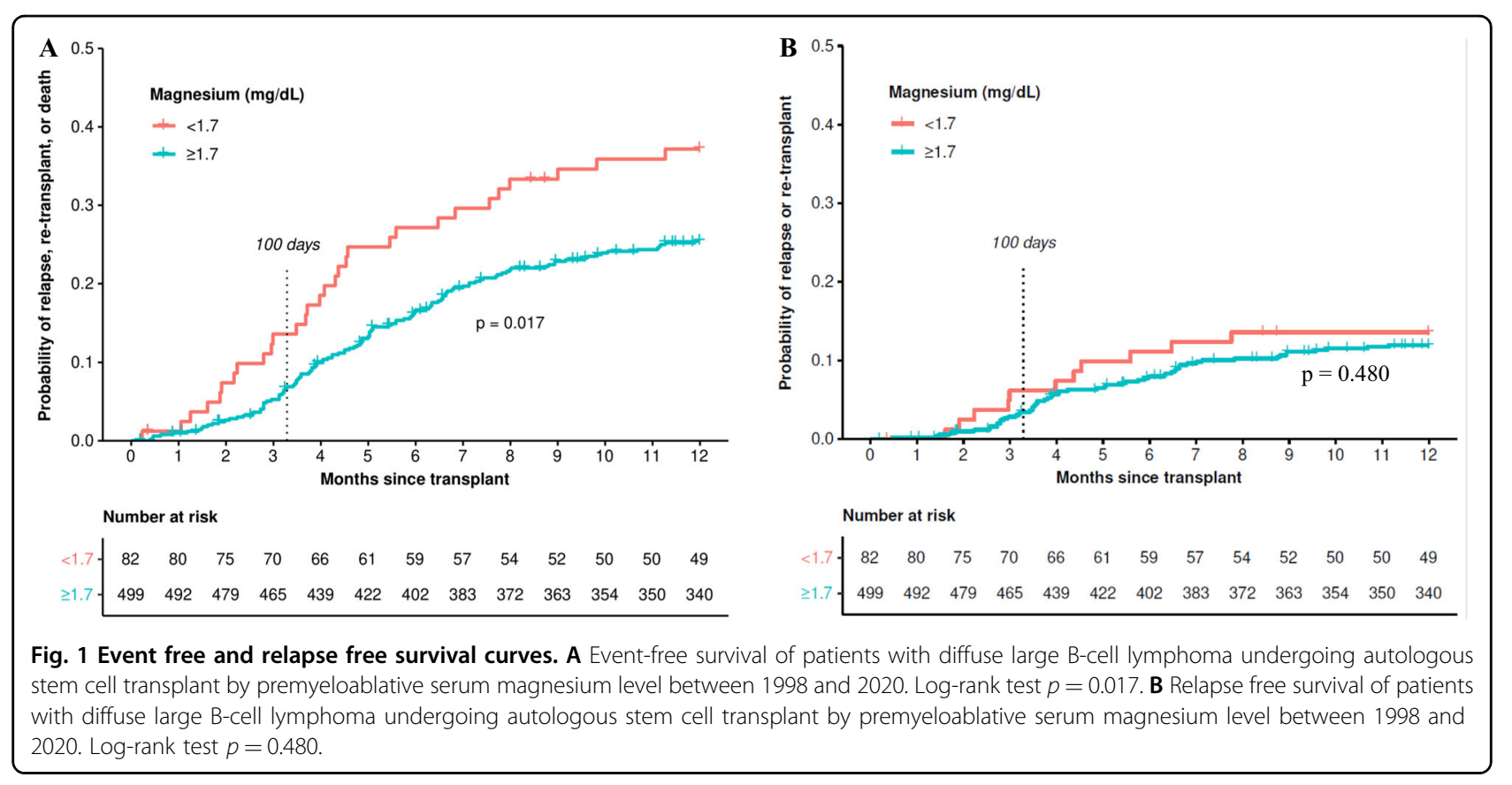

\section{Overall and event-free survival}

Median follow-up following transplantation was 3.0 years (range: $0.1-21.3$ years). Since the focus was on the role of a single pretransplant magnesium level on EFS and OS, we evaluated the magnesium level with respect to two key landmarks used in AHSCT-day +100 and 1 year.

For the outcome of EFS (Fig. 1A), 7.8\% (45/581) of patients had an event by day 100 and 26.3\% (153/581) had an event by month 12 . Of these 153 patients with an event during the 12 months following SCT, 55\% (84/153) died without known relapse or retransplant; an additional 29 (19\%) deaths were associated with relapse; and 40 (26\%) relapses/retransplants did not die in the first year. Median EFS for patients with hypomagnesemia was estimated to be 3.9 years (95\% CI: $1.63-8.98$ years) vs. 6.29 years $(95 \%$ CI: 4.73-8.95 years) for patients with serum magnesium levels within RR. Day +100 EFS was estimated to be $86.4 \%$ (95\% CI: 79.3-94.2\%) in those patients with hypomagnesemia vs. 93.1\% (95\% CI: 90.9-95.4\%) in patients with serum magnesium levels within RR. EFS at 1 year for patients with hypomagnesemia was estimated at $62.8 \%$ (95\% CI: $53.1-74.3 \%$ ) compared to $74.6 \%$ (95\% CI: 70.8-78.6\%) for patients with serum magnesium levels within RR. For EFS up to 1 year, the hazard ratio (HR) for hypomagnesemia estimated from a Cox model was 1.63 (95\% CI: $1.09-2.43, p=0.017$ ). The impact of hypomagnesemia on EFS was primarily on non-relapse mortality (Fig. 1B); there was no significant difference in lymphoma relapse rate between patients with hypomagnesemia and serum magnesium levels within the RR $(p=0.480)$.
There were 28 deaths (4.8\%) observed in the first 100 days following transplantation, and 113 (19.4\%) within the first year. OS at day 100 and 12 months was also worse for those with baseline hypomagnesemia. The median OS was estimated to be 7.3 years (95\% CI: $2.91-$ upper limit not estimable) for patients with hypomagnesemia vs. 9.7 years (95\% CI: 6.92-12.3 years) for patients with serum magnesium levels within RR. Day 100 OS for patients with hypomagnesemia vs. those with serum magnesium levels within RR was estimated at 90.1\% (95\% CI: $83.9-96.9 \%)$ and $96.0 \%$ (95\% CI: 94.2-97.7\%), respectively. OS at 1 year for patients with hypomagnesemia vs. serum magnesium levels within RR was $69.0 \%$ (95\% CI: 59.6-79.9\%) and 81.7\% (95\% CI: 78.3-85.3\%), respectively. For OS up to 1 year, the estimated HR for hypomagnesemia was 1.90 (95\% CI: $1.22-2.96, p=0.005)$ (Fig. 2).

Our cohort spans a 22-year time period and some standard of care transplant practices have changed in the last 2 decades. We, therefore, performed a survival analysis restricted to patients transplanted in the last 10 years. For patients with hypomagnesemia treated between 2010 and $2020(n=425)$, the OS HR for hypomagnesemia was 2.03 (95\% CI: 1.16-3.54), $p=0.013$ (Fig. 3). For patients treated 1998-2010 $(n=156)$, the OS HR for hypomagnesemia trended in a similar direction at 1.60 (95\% CI: $0.77-3.36), p=0.2$.

Table 2 shows the univariate and multivariate analyses of factors related to OS up to 1-year post AHSCT. Higher serum magnesium (HR 0.199 per doubling, 95\% CI: $0.078-0.503 ; p<0.001$ ) and higher albumin (HR 0.090 per 


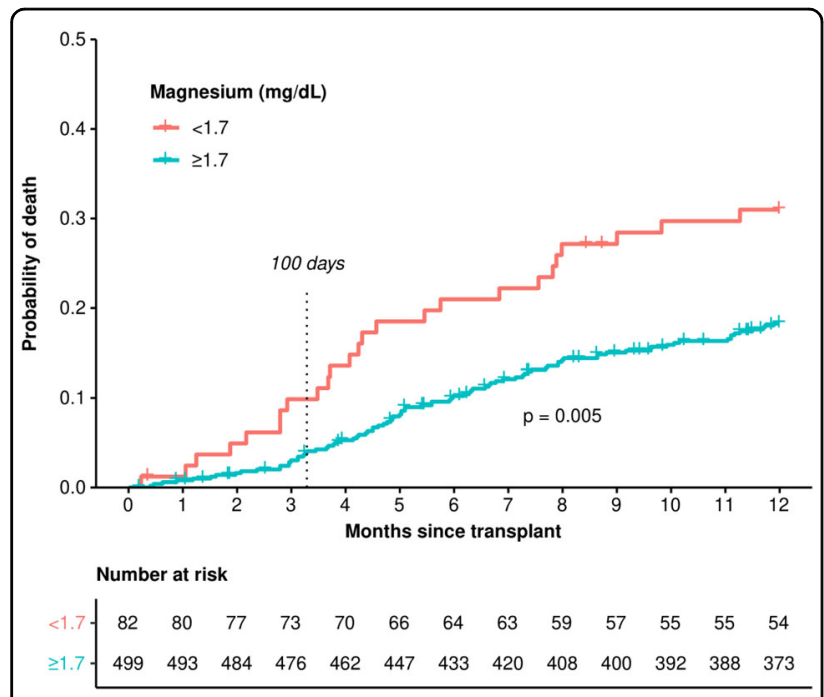

Fig. 2 Overall survival of patients with diffuse large B-cell lymphoma undergoing autologous stem cell transplant by premyeloablative serum magnesium level between 1998 and 2020. Log-rank test $p=0.005$.

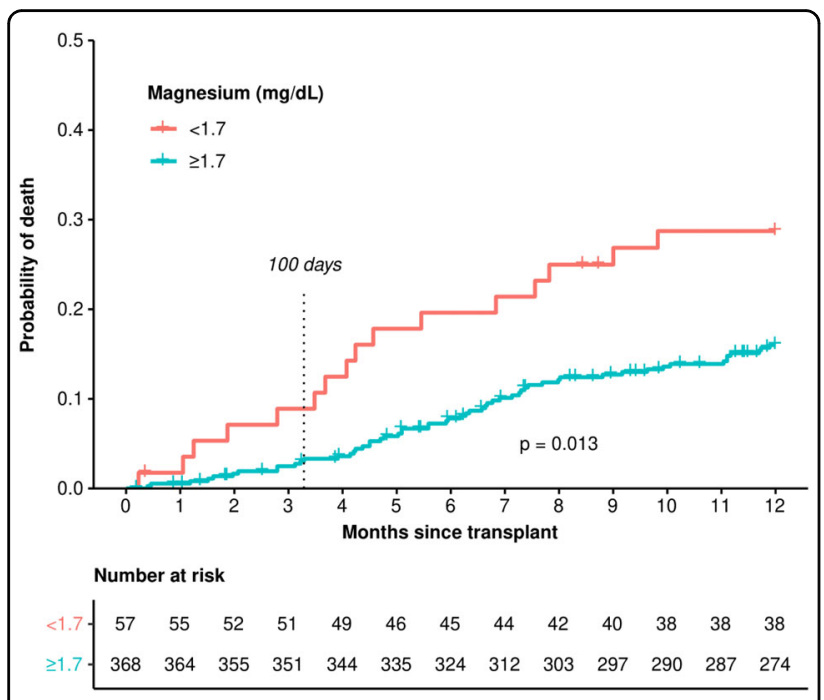

Fig. 3 Overall survival of patients with diffuse large B-cell lymphoma undergoing autologous stem cell transplant by premyeloablative serum magnesium level between 2010 and 2020. Log-rank test $p=0.013$.

doubling, 95\% CI: 0.021-0.394; $p=0.001$ ) were associated with lower mortality rates; whereas, higher serum creatinine (HR 1.669 per doubling, 95\% CI: 1.066-2.614; $p=0.025)$ was associated with greater mortality up to 1year post-AHSCT. In a multivariate Cox regression without albumin, lower magnesium $(p<0.001)$ and higher creatinine $(p=0.038)$ were independent predictors of inferior OS (Table 2). Calcium levels and liver function tests were not significantly associated with OS. When albumin was included, both lower magnesium $(p=0.004)$ and lower albumin $(p=0.002)$ were independent predictors of inferior OS.

Since a low serum magnesium level predicted an inferior outcome after AHSCT, we investigated what level of serum magnesium was best for predicting low vs. highrisk patients. Using proportional hazards regression of EFS and OS (Fig. 4) on the continuous magnesium level and using cubic splines to allow for a nonlinear relationship, we determined that a magnesium level of $2.0 \mathrm{mg} / \mathrm{dL}$ should be considered as a reasonable target for future studies. The hazard of death (or relapse or retransplantation), estimated as a function of magnesium level, decreased most rapidly as magnesium increased through $2.0 \mathrm{mg} / \mathrm{dL}$ (Fig. 4).

Finally, we performed analysis restricted to patients with at least two magnesium levels prior to undergoing conditioning in preparation for AHSCT to see whether the combination or trend of multiple magnesium levels might be more informative about survival than the last magnesium level alone. As demonstrated in Fig. 5, the value closest to day -7 was most predictive of outcome.

\section{Day +15 ALC recovery after transplant}

There was no significant difference between baseline ALC values in patients with serum magnesium levels within RR vs. low magnesium levels (Table 1). In addition, the day +15 ALC recovery level between patients with serum magnesium levels within RR and low serum magnesium levels was not significantly different (Table 3 ).

\section{Discussion}

Abnormalities of serum magnesium are common in hospitalized patients. A very large study found that of over 11,000 patients hospitalized with malignant diseases, 33\% had hypomagnesemia and those patients had a higher risk of in-hospital mortality ${ }^{21}$. Serum magnesium, although commonly included in laboratory studies in hospitalized patients, is not routinely measured in new, untreated lymphoma patients in the outpatient setting. However, serum magnesium is measured in the AHSCT setting and replaced as needed during the peritransplant period. The goal is to normalize the serum magnesium with no specific target other than to achieve a value within the RR. The increase in-hospital mortality with hypomagnesemia in addition to the association of XMEN disease with lymphoma led to this study in DLBCL patients receiving AHSCT. Indeed, we found that $14 \%$ of patients with DLBCL undergoing AHSCT had hypomagnesemia pretransplant and they had inferior outcomes at day 100 and at 1 year. The exact cause of the hypomagnesemia is difficult to discern in this patient population but is likely due to poor dietary intake due to symptoms from relapsed DLBCL, diuretics, renal dysfunction, and previous 
Table 2 Univariate and multivariate analysis of vs overall survival at 1 year (Cox proportional hazards regression model using continuous variables).

\begin{tabular}{|c|c|c|c|c|c|c|}
\hline \multirow[b]{2}{*}{ Variables } & \multicolumn{3}{|c|}{ Univariate analysis } & \multicolumn{3}{|c|}{ Multivariate analysis } \\
\hline & HR & $95 \% \mathrm{Cl}$ & $p$ Value & HR & $95 \% \mathrm{Cl}$ & $p$ Value \\
\hline Age, per 10 years & 0.99 & $0.85-1.15$ & 0.89 & & & \\
\hline Male gender & 1.26 & $0.85-1.85$ & 0.25 & & & \\
\hline Higher serum magnesium values & 0.2 & $0.08-0.50$ & $<0.001$ & 0.21 & $0.08-0.53$ & $<0.001$ \\
\hline Higher absolute lymphocyte count at baseline & 0.9 & $0.77-1.06$ & 0.22 & & & \\
\hline Higher platelet count at baseline & 0.84 & $0.66-1.06$ & 0.15 & & & \\
\hline Higher serum albumin & 0.09 & $0.02-0.39$ & 0.001 & & & \\
\hline Higher serum creatinine & 1.67 & $1.07-2.61$ & 0.03 & 1.61 & $1.03-2.52$ & 0.04 \\
\hline
\end{tabular}
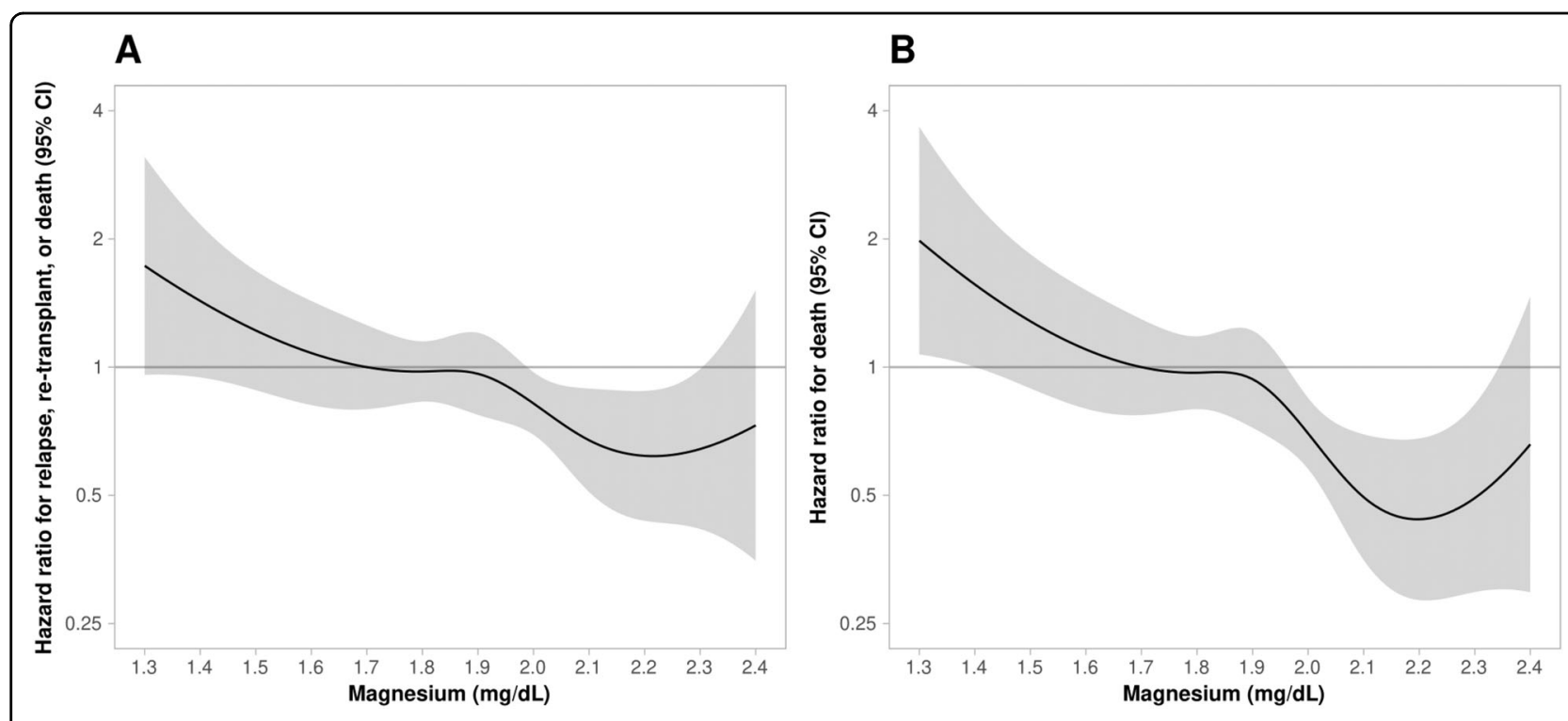

Fig. 4 Hazard of death estimated as a function of magnesium level. Log-scale hazard of $\mathbf{A}$ event-free survival and $\mathbf{B}$ overall survival up to 1 year following transplant by serum magnesium $(\mathrm{mg} / \mathrm{dL})$ drawn prior to myeloablative conditioning. The shaded areas represent the confidence intervals.

platinum-based chemotherapy ${ }^{22,23}$. We also found that over half of the events that the patients experienced in the first year were not associated, as best we could discern, with relapse of the DLBCL. This indicates a potential role for magnesium in all-cause mortality post-DLBCL SCT as shown by others for all hospitalized patients ${ }^{21}$. This finding is similar to studies on the gut microbiome in patients undergoing allogeneic stem cell transplant where the microbial diversity changes impacted primarily nonrelapse mortality and not a relapse of the tumor ${ }^{24}$.

There have been only a few other studies of magnesium and lymphoma but none specifically in DLBCL or the transplant setting. Merza et al. ${ }^{25}$ studied 55 patients with blood cancers (7 NHL) and found 4/7 to have a low level compared to control patients. In addition, our group also recently investigated the incidence of hypomagnesemia in 61 patients with Burkitt Lymphoma prior to chemotherapeutic treatment and found hypomagnesemia in $16 \%$. Those patients with hypomagnesemia also had an inferior OS $^{19}$.

Our study also found a significant association between low serum magnesium levels and thrombocytopenia. Others have shown thrombocytopenia to be a predictor for poor prognosis in patients with $\mathrm{DLBCL}^{26}$; however, thrombocytopenia in our dataset was not predictive of the inferior OS at 1 year. We are not aware of a mechanism that would link magnesium to megakaryocyte function thus this association likely reflects the disease state and prior treatment the patient received. Elevated creatinine was also associated with low magnesium levels and both 


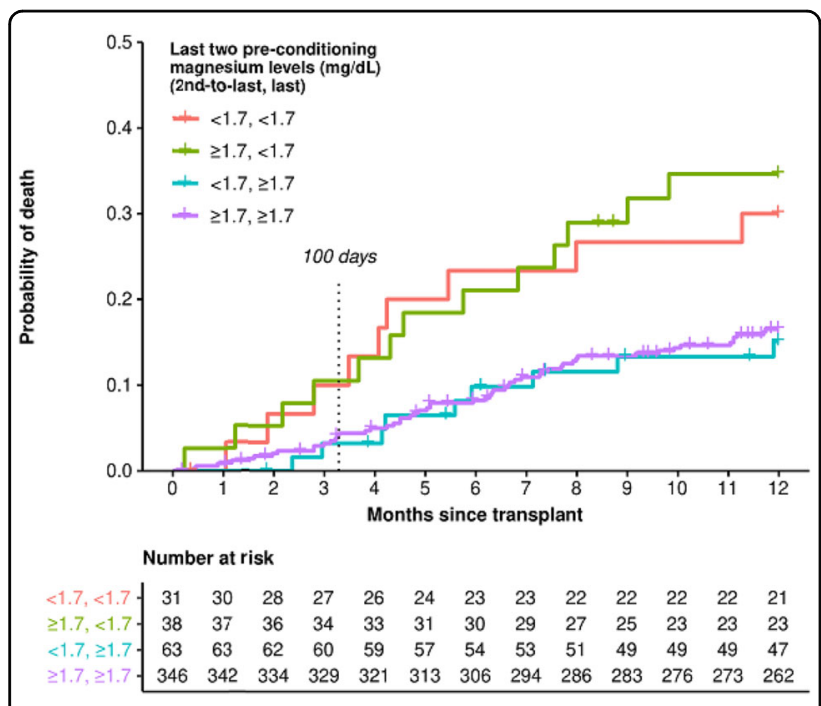

Fig. 5 Overall survival stratified by magnesium levels. Overall survival of patients with diffuse large B-cell lymphoma undergoing autologous stem cell transplant by the two most recent premyeloablative serum magnesium levels.

Table 3 Day 15 lymphocyte recovery by premyeloablative serum magnesium level.

\begin{tabular}{llll}
\hline $\begin{array}{l}\text { Day } \mathbf{1 5} \text { absolute } \\
\text { lymphocyte recovery }\end{array}$ & $\begin{array}{l}\text { Mg within the } \\
\text { reference range } \\
\mathbf{N}=\mathbf{4 9 9}\end{array}$ & $\mathbf{N = \mathbf { 8 2 }}$ & \\
\hline $\begin{array}{l}\text { Absolute lymphocyte } \\
\text { count }<0.5 \times 10^{9} / \mathrm{L}\end{array}$ & $221(44.4 \%)$ & $39(47.6 \%)$ & 0.591 \\
Absolute lymphocyte & $277(55.6 \%)$ & $43(52.4 \%)$ & \\
count $>0.5 \times 10^{9} / \mathrm{L}$ & & & \\
\hline
\end{tabular}

Mg magnesium.

increased creatinine and lower magnesium were independently associated with inferior OS. These associations are understandable given the kidney's role in magnesium homeostasis via reabsorption at the Loop of Henle ${ }^{27}$. Renal handling of magnesium is affected when kidney function declines ${ }^{23}$.

Serum albumin is also a prognostic marker in DLBCL ${ }^{28}$. Alterations in circulating albumin levels have been shown to affect magnesium levels ${ }^{29}$, similar to calcium as about one-third of extracellular magnesium is bound to proteins ${ }^{18}$. However, we did not find an association between hypoalbuminemia and hypomagnesemia in this study.

Based on previous studies examining the role of magnesium and the immune system, we hypothesized that hypomagnesemia patients with DLBCL undergoing ASCHT would have poor outcomes and that this could be associated with impaired lymphocyte recovery after stem cell reinfusion. Previous studies have found that the day 15 ALC (ALC-15) after AHSCT is a significant predictor for survival in DLBCL ${ }^{10}$. From a numerical standpoint, we did not find any difference in ALC recovery between the magnesium sufficient and deficient groups. However, magnesium is an important nutrient for immune function $^{30}$ and it is possible that lymphocyte function (not absolute number) could be impaired due to low serum magnesium leading to impaired EFS/OS. Future studies will need to include functional studies along with magnesium replacement to better understand these associations and mechanism(s).

The strengths of our study include a large cohort at one institution with the same lymphoma transplant team evaluating each patient for selection for AHSCT. As a result, there was a unified approach to patient selection and treatment. In addition, the median follow-up time after transplantation was 3.0 years with a focus on year 1 . We selected early endpoints to compare with serum magnesium pretransplant as patients who fail SCT typically do so early.

There are some limitations to our study. The patients were accrued over a 22-year period; however, the conditioning regimens have changed little over that time period and we demonstrated that our findings are still relevant in the most recent decade (Fig. 3). We also were unable in this retrospective study to clearly determine the cause of the magnesium deficiency. Although platinumbased chemotherapy can impair renal function, the impact of low serum magnesium on outcome was demonstrated to be independent of albumin and creatinine. We also did not evaluate the role of magnesium levels determined after the start of the conditioning regimen nor after day 0 stem cell reinfusion. After these time points, the patients were evaluated and treated daily by the team, and magnesium deficiency typically replaced with IV or oral replacement.

These data provide a rationale to consider a magnesium replacement strategy for hypomagnesemia patients going to transplant. If a replacement is commenced, what should be the target? Our study provides valuable and useful data for clinicians. The hazard of death for these DLBCL patients, estimated as a function of magnesium level, decreased most rapidly as the serum magnesium increased to $2.0 \mathrm{mg} / \mathrm{dL}$. Although $1.7 \mathrm{mg} / \mathrm{dL}$ is technically within the reference range, in a subset of cardiovascular patients, levels less than $2.0 \mathrm{mg} / \mathrm{dL}$ have been shown to be associated with an increased risk of sudden cardiac death $^{31,32}$. In general, cardiology patients have magnesium levels aggressively replaced to a target of $2.0 \mathrm{mg} / \mathrm{dL}$, because of this increased risk of cardiac death ${ }^{33}$. In this DLBCL AHSCT study, the hazard rate for relapse reached 1 at the $1.9-2.0 \mathrm{mg} / \mathrm{dL}$ level indicating that a level of $2.0 \mathrm{mg} / \mathrm{dL}$ is also a reasonable target. Recent work has also 
suggested that the current reference range of magnesium is too $l^{3} w^{34}$ and further research into the conventional serum magnesium levels is needed.

Although we have demonstrated the importance of low magnesium with respect to outcome, the key next question is whether magnesium replacement in this subset (14\%) of relapsed DLBCL patients with hypomagnesemia will actually improve outcome. A low magnesium level may simply be another biomarker of illness and replacement of magnesium to the reference range levels prior to AHSCT may not improve outcomes. Interestingly, we found that the magnesium level just prior to conditioning therapy and AHSCT is most important for predicting outcomes in patients after transplant, regardless of previous serum magnesium levels. Thus, magnesium replacement at this important time point needs to be addressed prospectively given that this is a low-cost approach to further improve AHSCT outcomes. The peri-transplant period offers an ideal time to test these future magnesium strategies as diet and magnesium levels can be carefully monitored in the transplant setting. Lastly, we were unable to demonstrate the impact of hypomagnesemia on ALC recovery at day 15. Future studies should evaluate magnesium levels in association with $\mathrm{T}$ - and B-cell function as it is likely that it is the functional defect that is more important than the numerical deficiency.

\section{Acknowledgements}

This study was supported in part by the Mayo Clinic Bone Marrow Transplant Database. Supported in part by the University of lowa/Mayo Clinic Lymphoma SPORE (CA97274-19)

\section{Author details}

'Division of Hematology, Department of Medicine, Mayo Clinic Rochester, Rochester, MN 55905, USA. ${ }^{2}$ Department of Biomedical Statistics and Informatics, Mayo Clinic Rochester, Rochester, MN 55905, USA. ${ }^{3}$ Division of Endocrinology, Department of Medicine, Mayo Clinic Rochester, Rochester, MN 55905, USA. ${ }^{4}$ Department of Laboratory Medicine and Pathology, Mayo Clinic Rochester, Rochester, MN 55905, USA

\section{Conflict of interest}

The authors declare no competing interests.

\section{Publisher's note}

Springer Nature remains neutral with regard to jurisdictional claims in published maps and institutional affiliations.

Received: 26 August 2020 Revised: 6 February 2021 Accepted: 10 February 2021

Published online: 26 March 2021

\section{References}

1. Salar, A. et al. Distribution and incidence rates of lymphoid neoplasms according to the REAL classification in a single institution. A prospective study of 940 cases. Eur. J. Haematol. 59, 231-237 (1997)

2. Habermann, T. M. et al. Rituximab-CHOP versus CHOP alone or with maintenance rituximab in older patients with diffuse large B-cell lymphoma. J. Clin. Oncol. 24, 3121-3127 (2006).
3. Coiffier, B. \& Sarkozy, C. Diffuse large B-cell lymphoma: R-CHOP failure-what to do? Hematol. Am. Soc. Hematol. Educ. Program 2016, 366-378 (2016).

4. Maurer, M. J. et al. Event-free survival at 24 months is a robust end point for disease-related outcome in diffuse large B-cell lymphoma treated with immunochemotherapy. J. Clin. Oncol. 32, 1066-1073 (2014).

5. Gisselbrecht, C. \& Van Den Neste, E. How I manage patients with relapsed/ refractory diffuse large B cell lymphoma. Br. J. Haematol. 182, 633-643 (2018).

6. González-Barca, E. et al. Outcome in patients with diffuse large B-cell lymphoma who relapse after autologous stem cell transplantation and receive active therapy. A retrospective analysis of the Lymphoma Working Party of the European Society for Blood and Marrow Transplantation (EBMT). Bone Marrow Transpl. 55, 393-399 (2020).

7. Philip, T. et al. Autologous bone marrow transplantation as compared with salvage chemotherapy in relapses of chemotherapy-sensitive non-Hodgkin's lymphoma. N. Engl. J. Med. 333, 1540-1545 (1995).

8. Nagle, S. J. et al. Outcomes of patients with relapsed/refractory diffuse large B-cell lymphoma with progression of lymphoma after autologous stem cell transplantation in the rituximab era. Am. J. Hematol. 88, 890-894 (2013).

9. Vose, J. M. et al. Progressive disease after high-dose therapy and autologous transplantation for lymphoid malignancy: clinical course and patient followup. Blood 80, 2142-2148 (1992).

10. Porrata, L. F. et al. Early lymphocyte recovery predicts superior survival after autologous stem cell transplantation in non-Hodgkin lymphoma: a prospective study. Biol. Blood Marrow Transpl. 14, 807-816 (2008).

11. Porrata, L. F., Ingle, J. N., Litzow, M. R., Geyer, S. \& Markovic, S. N. Prolonged survival associated with early lymphocyte recovery after autologous hematopoietic stem cell transplantation for patients with metastatic breast cancer. Bone Marrow Transpl. 28, 865-871 (2001).

12. Kansagra, A. et al. Infusion of autograft natural killer cell/CD14(+)HLA-DR(DIM) cell ratio predicts survival in lymphoma post autologous stem cell transplantation. Bone Marrow Transpl. 53, 146-154 (2018).

13. Stiff, P. et al. Treatment with plerixafor in non-Hodgkin's lymphoma and multiple myeloma patients to increase the number of peripheral blood stem cells when given a mobilizing regimen of G-CSF: implications for the heavily pretreated patient. Biol. Blood Marrow Transpl. 15, 249-256 (2009).

14. Neelapu, S. S. et al. Axicabtagene ciloleucel CAR T-cell therapy in refractory large B-cell lymphoma. N. Engl. J. Med. 377, 2531-2544 (2017).

15. Li, F. Y. et al. XMEN disease: a new primary immunodeficiency affecting Mg2+ regulation of immunity against Epstein-Barr virus. Blood 123, 2148-2152 (2014).

16. Ravell, J. C. et al. Defective glycosylation and multisystem abnormalities characterize the primary immunodeficiency XMEN disease. J. Clin. Investig. 130, 507-522 (2020).

17. Ravell, J., Chaigne-Delalande, B. \& Lenardo, M. X-linked immunodeficiency with magnesium defect, Epstein-Barr virus infection, and neoplasia disease: a combined immune deficiency with magnesium defect. Curr. Opin. Pediatr. 26, 713-719 (2014).

18. Gile, J., Ruan, G., Abeykoon, J., McMahon, M. M. \& Witzig, T. Magnesium: the overlooked electrolyte in blood cancers? Blood Rev. 44, 100676 (2020).

19. Gile, J. et al. Hypomagnesemia is associated with an increased risk of early clinical failure in patients with Burkitt lymphoma. Leukemia Lymphoma 61, 1-3 (2020).

20. Goel, M. K., Khanna, P. \& Kishore, J. Understanding survival analysis: KaplanMeier estimate. Int. J. Ayurveda Res. 1, 274-278 (2010).

21. Cheungpasitporn, W., Thongprayoon, C. \& Qian, Q. Dysmagnesemia in hospitalized patients: prevalence and prognostic importance. Mayo Clin. Proc. 90, 1001-1010 (2015)

22. Ravasco, P. Nutrition in Cancer Patients. J. Clin. Med. https://doi.org/10.3390/ jcm8081211 (2019).

23. Cunningham, J., Rodríguez, M. \& Messa, P. Magnesium in chronic kidney disease Stages 3 and 4 and in dialysis patients. Clin. Kidney J. 5, i39-i51 (2012).

24. Peled, J. U. et al. Microbiota as Predictor of Mortality in Allogeneic Hematopoietic-Cell Transplantation. N. Engl. J. Med. 382, 822-834 (2020).

25. Merza, W., Majid, A., Daoud, M. \& Almothaffar, A. Serum magnesium concentration in patients with leukemia and lymphoma. J. Fac. Med. Baghdad 52, 101-104 (2008) 
26. Chen, L. P., Lin, S. J. \& Yu, M. S. Prognostic value of platelet count in diffuse large B-cell lymphoma. Clin. Lymphoma Myeloma Leuk. 12, 32-37 (2012).

27. Jahnen-Dechent, W. \& Ketteler, M. Magnesium basics. Clin. Kidney J. 5, i3-i14 (2012).

28. Dalia, S. et al. Serum albumin retains independent prognostic significance in diffuse large B-cell lymphoma in the post-rituximab era. Ann. Hematol. 93 1305-1312 (2014).

29. Kroll, M. H. \& Elin, R. J. Relationships between magnesium and protein concentrations in serum. Clin. Chem. 31, 244-246 (1985).

30. Tam, M., Gómez, S., González-Gross, M. \& Marcos, A. Possible roles of magnesium on the immune system. Eur. J. Clin. Nutr. 57, 1193-1197 (2003).
31. Kieboom, B. C. et al. Serum magnesium and the risk of death from coronary heart disease and sudden cardiac death. J. Am. Heart Assoc. https://doi.org/ 10.1161/jaha.115.002707 (2016).

32. An, G. et al. Association between low serum magnesium level and major adverse cardiac events in patients treated with drug-eluting stents for acute myocardial infarction. PLOS ONE 9, e98971 (2014).

33. DiNicolantonio, J. J., Liu, J. \& O'Keefe, J. H. Magnesium for the prevention and treatment of cardiovascular disease. Open Heart 5, e000775 (2018).

34. Costello, R. B. et al. Perspective: the case for an evidence-based reference interval for serum magnesium: the time has come. Adv. Nutr. 7, 977-993 (2016). 